\title{
Special issue on accounting and auditing
}

\author{
Michael T. Kirschenheiter • Dirk Simons • \\ Jeroen Suijs
}

Published online: 3 March 2011

(C) Springer-Verlag 2011

\section{Introduction}

It is perhaps little known that accounting and mathematics have been connected for more than 500 years ago. In 1494, Luca Pacioli published his mathematics compendium Summa de Arithmetica, Geometria, Proportioni et Proportionalita consisting of 615 pages. "[T]he only significant part of the book that has ever been translated to English" was the 27-page treatise on bookkeeping, ${ }^{1}$ which defines the hour of birth of accounting. So to speak the study of double entry accounting was developed in concert with linear algebra. ${ }^{2}$ Beyond the joint development, which becomes apparent in Pacioli's book, there are several reasons why accounting offers a very good application for mathematical techniques and mathematical knowledge. First, accounting phenomena cannot be understood best by just observing them. For generating predictions and interpretations [analytical] theory is required. ${ }^{3}$ Second, formalizing economic arguments by means of a mathematical model results in a more rigorous

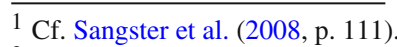

2 Cf. Fellingham (2007, p. 161).

3 Cf. Watts (1982, p. 49).
}

\section{T. Kirschenheiter}

Department of Accounting, University of Illinois at Chicago, 601 S. Morgan Street,

Chicago, IL 60607-7123, USA

e-mail: mkirsche@uic.edu

D. Simons $(\varangle)$

Department of Accounting, University of Mannheim, Schloss-Ostflügel, 68131 Mannheim, Germany e-mail: simons@bwl.uni-mannheim.de

\section{J. Suijs}

Department of Accountancy, Tilburg University, P. O. Box 90153, 5000 LE Tilburg, The Netherlands e-mail: jeroen.suijs@tilburguniversity.edu 
presentation. ${ }^{4}$ With accounting and auditing becoming international, it is more important than ever to have a common ground for discussion that is not hampered by any language barriers. This common ground is provided by mathematical and analytical methods, like agency theory or game theory. ${ }^{5}$ Third, accounting and auditing are highly regulated by national and international standards. If standard setting processes comprise strategic behavior by and strategic interactions (in the sense of game theory) between companies, investors and auditors then our analysis of these interactions may benefit from game theoretical models. More generally, accounting theory cannot only rely on normative standards. ${ }^{6}$

The objective of this special issue of OR Spectrum is to emphasize the impacts of accounting and auditing regimes on the behavior of rational agents acting in this environment. The set of papers presented here covers auditing, financial accounting, managerial accounting, and tax accounting highlighting the importance of strategic behavior in all these sub-disciplines of accounting.

\section{Auditing-audit regulation and auditor reputation}

The first paper, authored by Wuchun Chi, contributes to audit regulation theory. It analyzes the impacts of mandatory auditor rotation on the possibility of collusion between manager and auditor. The advantage of changing the audit company after a pre-specified period of time is to avoid familiarity between the client and the auditor. The disadvantage is that gains resulting from learning effects are lost. Whether the net-effect is positive or negative is unclear. In this context, analytical modeling is applied for two reasons: First, the standard-oriented, normative debate left unnoticed certain drawbacks of mandatory audit regulation. Second, only very few countries implemented mandatory audit rotation, implying that empirical data is lacking. Thus, modeling is the most adequate way of gaining deeper insights. The model compares the optimal audit committee investigation strategy and the optimal audit fees in a rotation and a non-rotation regime. The author concludes that under a rotation-regime the audit committee adopts a more aggressive investigation strategy, i.e. more effort is provided. Further, audit fees will be higher compared with a non-rotation regime.

The paper by Jochen Bigus is the second paper contributing to audit regulation. Here, auditor liability's interaction with potential reputation losses and overcompensation is analyzed. The paper distinguishes between (individual) economic losses and social losses showing that even in the absence of punitive damages, i.e. only the real economic loss is compensated, reputation and overcompensation induce an excessive care level provided by the auditor, i.e., the audit effort exceeds the overall optimum. However, this effect can be alleviated by a properly defined liability cap. Interestingly, standard setters started discussing to abandon liability caps a few years ago, but have only been able to agree that limited liability has beneficial effects.

\footnotetext{
4 Cf. Verrecchia (1982, p. 39).

5 For a review cf. Kanodia (2002, pp. 49).

6 Cf. Demski (1973, p. 721). For the implications of this insight cf. Antle et al. (2007, p. xvii).
} 


\section{Incentive effects of corporate governance and financial accounting}

If auditing is seen as a corporate governance device, then the paper by Thorsten Döscher and Gunther Friedl bridges the gap between the audit papers presented above and the following contributions from financial accounting. Assuming that the board of directors has a major influence on managerial compensation, the authors investigate the question whether CEOs have the power to influence both level and structure of their own compensation directly or indirectly. For this purpose, a principal-agent model is designed, where the shareholders as principal contract both the board of directors and the CEO. The latter can influence the firm value by spending individual effort, whereas the former tries to learn about the manager's ability. By doing so, the board helps in adjusting the compensation parameters more properly. By initiating collusive behavior, the CEO has the opportunity to influence the board by persuading the board not to convey this information. As expected, shareholders adjust the optimal contracts to prevent the agents from colluding. In contrast to conventional wisdom, this may cause a highly skilled manager's compensation to decrease in equilibrium.

In analytical models, accounting is often interpreted as an information device, providing performance measures for contracting purposes. However, the appropriateness of accounting data might change with the set of available information sources. This is why a partial equilibrium view of the world might generate misleading results. The paper by Mirko Heinle and Christian Hofmann builds upon this effect when investigating the consequences of publicly reported soft information from a contracting perspective. They present a model where the set of performance measures which is observable to investors is changed in the compared settings. Accordingly, aggregation of information in prices is altered, inducing different optimal incentive rates and different payoffs to the principal. If soft information is available to investors, a less congruent market price can result, leading to inefficient effort allocations of the agent and leaving the principal worse-off.

A similar problem is modeled by Anja De Waegenaere and Jacco Wielhouwer. They consider a principal-agent setting where the manager selects an accounting method from a set of accounting options. Hence, the manager directly influences his performance measure. Focusing on the degree of discretion, the paper demonstrates that the minimum degree of discretion may be necessary for contracting. This is an interesting result, because negotiation theory suggests that enlarging the negotiation space should simplify the contracting. However, the argument presented here works slightly different: With a sufficiently small degree of reporting flexibility, incentive problems are mitigated, allowing for lower bonus payments and leaving the principal better off. With a sufficiently high level of accounting flexibility, incentive problems are increased, but compensation risk is decreased, implying that the net-effect on the principal's payoff is unclear. Introducing limited liability the manager's payoff always improves, but the principal only benefits, if accounting choices are limited. 


\section{Managerial accounting-accounting information in supply chains}

In contrast to the previous papers, Hanne Böckem and Ulf Schiller focus on the value of ignorance. The considered setting represents a supply chain where a manufacturer determines the terms of a supply credit when contracting a dealer who is liquidity constrained. The paper's objective is to identify conditions under which the dealer's limited liability has a significant influence on the optimal contract's shape. With no liquidity, the optimal supply credit contract pools ignorant dealers and informed dealers with unfavorable information while informed dealers with favorable information are screened. With an intermediate level of liquidity, all dealers are screened and with very high liquidity ignorant dealers and dealers with favorable information are pooled.

\section{Tax accounting —optimal tax depreciation strategies}

Anja De Waegenaere and Jacco Wielhouwer also contribute a second paper to this special issue. Their paper "Dynamic tax depreciation strategies" develops a framework for the well-known objective of minimizing the net present value of tax payments. The authors incorporate an option to negotiate with fiscal authorities about changes of the depreciation method. Thus, it can be analyzed how loss carry forwards and changes of the depreciation method interact. Interestingly, the existence of loss carry forwards increases the value of the option to change the depreciation method, although the overall tax burden is reduced by loss carry forwards. This effect occurs because loss carry forwards allow managers to exercise the (real) option of changing the depreciation method earlier compared to settings without loss carry forwards.

Acknowledgments The guest editors would like to thank the managing editor for giving the opportunity to realize this special issue. Further, we thank all submitting authors for their interesting and insightful papers. Overall, we received 23 submissions from 10 different countries. This implies that approximately 50 reviewers contributed to this issue. We gratefully acknowledge their effort and their dedication. Without their excellent and timely refereeing this issue could not have been realized.

\section{References}

Antle R, Gjesdal F, Liang P-J (2007) Preface. In: Antle R, Gjesdal F, Liang P-J (eds) Essays in accounting theory in honour of Joel S. Demski, pp xvii-xix

Demski JS (1973) The general impossibility of normative accounting standards. Account Rev 48:718-723

Fellingham JC (2007) Is accounting an academic discipline. Accout Horizons 21:159-163

Kanodia C (2002) Game theory models in accounting. In: Chatterjee K, Samuelson WF (eds) Game theory and business applications. Kluwer, pp 49-94

Sangster A, Stoner GN, McCarthy P (2008) The market for Luca Pacioli’s Summa arithmetica. Account Historians J 35:111-134

Verrecchia RE (1982) The use of mathematical models in financial accounting. J Account Res 20(Suppl): $1-42$

Watts LE (1982) Discussion of the use of mathematical models in financial accounting. J Account Res 20(Suppl):48-55 